Research report

\title{
Cardiovascular dysfunction associated with neurodegeneration in an experimental model of Parkinson's disease
}

\author{
Barbara Falquetto $^{\mathrm{a}, 1}$, Marina Tuppy ${ }^{\mathrm{a}, 1}$, Simone R. Potje ${ }^{\mathrm{b}}$, Thiago S. Moreira ${ }^{\mathrm{c}}$, Cristina Antoniali ${ }^{\mathrm{b}}$, \\ Ana C. Takakura ${ }^{\mathrm{a}, *}$ \\ ${ }^{a}$ Department of Pharmacology, Institute of Biomedical Science, University of São Paulo, 05508-000 São Paulo, SP, Brazil \\ ${ }^{\mathrm{b}}$ Department of Basic Sciences, School of Dentistry of Araçatuba, UNESP-Univ. Estadual Paulista, 16015-050 Araçatuba, SP, Brazil \\ ${ }^{\mathrm{c}}$ Department of Physiology and Biophysics, Institute of Biomedical Science, University of São Paulo, 05508-000 São Paulo, SP, Brazil
}

\section{A R T I C L E I N F O}

\section{Article history:}

Received 29 July 2016

Received in revised form 6 December 2016

Accepted 7 December 2016

Available online 9 December 2016

\section{Keywords}

Parkinson disease

Baroreflex sensitivity

Vascular reactivity

Brainstem

\begin{abstract}
A B S T R A C T
Patients with Parkinson's disease (PD) exhibit both motor and non-motor symptoms. Among the nonmotor symptoms, cardiovascular autonomic dysfunction is frequently observed. Here, we evaluated baroreflex function, vascular reactivity and neuroanatomical changes in brainstem regions involved in the neural control of circulation in the 6-hydroxydopamine (6-OHDA) model of PD. Male Wistar rats received a bilateral injection of $6-\mathrm{OHDA}$ or vehicle into the striatum. After 61 days, baroreflex function and vascular reactivity were assessed. The 6-OHDA and vehicle groups showed similar increases in mean arterial pressure (MAP) in response to phenylephrine (PE). However, the bradycardia observed in the vehicle group was blunted in the 6-OHDA-treated rats. Injection of sodium nitroprusside (SNP) decreased hypotension, tachycardia and vascular relaxation in 6-OHDA-treated rats. Bilateral intrastriatal 6-OHDA led to massive degeneration of tyrosine hydroxylase $(\mathrm{TH})$-immunoreactive neurons in the substantia nigra and to reductions in the numbers of $\mathrm{A} 1 / \mathrm{C} 1$ and $\mathrm{A} 5$ catecholaminergic neurons while sparing $\mathrm{A} 2$ neurons within the nucleus of the solitary tract (NTS). 6-OHDA-treated rats also showed decreases in Phox2b-expressing neurons in the NTS and in choline acetyltransferase (ChAT) immunoreactivity in the nucleus ambiguus. Altogether, our data suggest that this model of PD includes neuroanatomical and functional changes that lead to cardiovascular impairment.
\end{abstract}

ㄷ 2016 Elsevier B.V. All rights reserved.

\section{Introduction}

Parkinson's disease (PD) is one of the most common neurodegenerative disorders. Clinically, it is well known by its motor symptoms such as bradykinesia, rigidity, tremor and postural instability. However, while the motor symptoms of PD are considered pathological hallmarks of the disease (Fearnley and Lees, 1991), several debilitating symptoms that substantially impair patients' quality of life are related to the non-motor aspects of PD (Wolters, 2009). Some common non-motor symptoms of PD include sleep disturbances, neuropsychiatric and cognitive deficits, sensory dysfunction, and breathing instability, as well as cardiovascular autonomic dysfunction (Bassetti, 2011; Chaudhuri et al., 2011; Dickson et al., 2009; Truong et al., 2008; Tuppy et al.,

\footnotetext{
* Corresponding author at: Department of Pharmacology, Institute of Biomedical Science, University of São Paulo, 1524, Prof. Lineu Prestes Avenue, 05508-000 São Paulo, SP, Brazil.

E-mail address: takakura@icb.usp.br (A.C. Takakura).

${ }^{1}$ B. Falquetto and M. Tuppy contributed equally to this study.
}

2015). There is no doubt that the motor symptoms of PD are associated with the loss of a specific group of dopaminergic neurons located in the substantia nigra (SN) and that this underlies the physiopathology of the disease; however, the specific populations of neurons responsible for various non-motor symptoms remain unclear. Orthostatic hypotension $(\mathrm{OH})$, the most common cardiovascular dysfunction in PD, results from the impairment of baroreflex function and cardiac sympathetic innervations (Cai et al., 2005; Tipre and Goldstein, 2005). Baroreflex dysfunction can also be associated with neurodegeneration in important regions of the brainstem. Previous reports show that the brainstems of patients with PD show considerable loss of an important adrenergic region involved in the neural control of circulation, i.e., the $\mathrm{C} 1$ region (Gai et al., 1993; Guyenet et al., 2013). However, according to other studies, patients with $\mathrm{PD}$ and $\mathrm{OH}$ showed marked individual variations in the numbers of catecholaminergic neurons in the $\mathrm{C} 1$ region, obscuring the correlations among $\mathrm{OH}, \mathrm{PD}$ and catecholaminergic neurons (Benarroch et al., 2000). Despite the controversial observations in patients with PD as described above, no previous studies have reported cardiovascular autonomic dysfunc- 
tion in a rat model of PD and its relationship with neurodegeneration in specific areas of the brainstem that are responsible for the neural control of blood pressure (Kuo et al., 2010; Lu et al., 1995; Takatsu et al., 2000). Here, we selected a widely used rat model of PD that is generated by injection of 6-hydroxydopamine (6OHDA) into the striatum. The neuroanatomical and functional assessment of cardiovascular involvement in the 6-OHDA model of PD may represent an important step for future clarification of the mechanisms underlying the appearance of cardiovascular autonomic dysfunction in PD.

Therefore, it is important to use the 6-OHDA model of PD to evaluate cardiovascular dysfunction, vascular reactivity and neuroanatomical changes in the brainstem regions involved in the neural control of circulation.

\section{Results}

\subsection{Animal model of Parkinson's disease: bilateral intrastriatal} injection of 6-OHDA destroyed tyrosine hydroxylase-expressing neurons of the substantia nigra

The 6-OHDA neurotoxic lesion within the nigrostriatal dopaminergic system is one of the most widely used methods to model PD in rodents (McDowell and Chesselet, 2012). In our study, 6-OHDA $(24 \mu \mathrm{g} / \mu \mathrm{L})$ was injected into the dorsal striatum of rats. The rostral-caudal extent of the lesion was determined by counting the neurons in the SN showing tyrosine hydroxylase immunoreactivity (TH-ir) in every sixth $40-\mu \mathrm{m}$ brain section from each rat (from 5.32 to $6.04 \mathrm{~mm}$ caudal to bregma). Compared to vehicleinjected control rats, 6-OHDA dramatically reduced the number of neurons showing $\mathrm{TH}-\mathrm{ir}$ in the $\mathrm{SN}(125 \pm 10$, vs. vehicle: $907 \pm 11$ neurons, $\mathrm{p}<0.001$ ) (Fig. $1 \mathrm{~A}, \mathrm{~B}$ and $\mathrm{I}$ ).

\subsection{Intrastriatal injection of 6-OHDA selectively reduces the number of brainstem neurons involved in cardiovascular function}

To further assess the effects of bilateral intrastriatal 6-OHDA on neurons involved in blood pressure control, at 61 days after the injections, TH-ir, choline acetyltransferase immunoreactivity (ChAT-ir) and Phox2b immunoreactivity (Phox2b-ir) were examined in the regions $\mathrm{A} 1 / \mathrm{C} 1, \mathrm{~A} 2 / \mathrm{C} 2$ and $\mathrm{A} 5$, in the dorsal motor nucleus of the vagus nerve (DMV) and in the nucleus ambiguus (NA), as well as in the intermediate and commissural regions of the nucleus of the solitary tract (NTSint and NTSc, respectively). In all regions analyzed, except for the A2/C2 and DMV, significant reductions in immunoreactive neurons were observed. For example, the numbers of neurons with $\mathrm{TH}$-ir that were counted in the A5 and $\mathrm{A} 1 / \mathrm{C} 1$ regions were reduced by $60 \%$ and $70 \%$, respectively, after 6-OHDA ( $24 \mu \mathrm{g}$ ) was injected into the striatum (A5: $43 \pm 1$, vs. vehicle: $107 \pm 5$ neurons and A1/C1: $123 \pm 14$, vs. vehicle: $404 \pm 2$ neurons, $\mathrm{p}<0.001$ ) (Fig. 1C-F and I). The numbers of cells showing ChAT-ir in the NA were decreased by $30 \%(191 \pm 20$, vs. vehicle: $269 \pm 13$ neurons, $\mathrm{p}<0.05$ ) (Fig. 2C-E). Nuclei in the NTSint and NTSc with Phox 2 b-ir were reduced by $48 \%$ and $73 \%$, respectively (Fig. 3A-E). Interestingly, the area of the NTS with reduced Phox2b-ir was the site of the first synapse of viscerosensory afferents in the brainstem, including those related to cardiorespiratory afferents (Ergene et al., 1994; Kang et al., 2007; Paton et al., 2001; Takakura et al., 2006). The Phox2b-expressing neurons in the NTS are presumably glutamatergic; they innervate the ventrolateral medulla and are collectively responsible for both the cardiovagal and the sympathetic components of the baroreflex (Chan and Sawchenko, 1994; Kang et al., 2007; Weston et al., 2003) (Fig. 3A-E). We also analyzed TH-ir in A2/C2 and ChAT-ir in the DMV; compared to control rats, intrastriatal 6-OHDA did not change the numbers of neurons showing $\mathrm{TH}$-ir in $\mathrm{A} 2 / \mathrm{C} 2$ or showing ChAT-ir in the DMV (Figs. 1G-I, 2A, B and E).

\subsection{Intrastriatal injection of 6-OHDA impaired cardiac baroreflex}

Analysis of the relationship between mean arterial pressure (MAP) and heart rate (HR) revealed a change in the sensitivity of the cardiac baroreflex in the 6-OHDA model of PD. The baroreflex (elicited by intravenous (IV) injections of either phenylephrine (PE) or sodium nitroprusside (SNP)) was tested 61 days after intrastriatal injection of 6-OHDA $(24 \mu \mathrm{g} / \mu \mathrm{L})$.

Baseline MAP and HR did not differ between 6-OHDA-lesioned and control rats $(113 \pm 1.25$ vs. vehicle: $110 \pm 0.7 \mathrm{mmHg}$ and $328 \pm 2.17$ vs. vehicle: $333 \pm 1.54 \mathrm{bpm}, \mathrm{p}>0.05)$. In control animals, injections of PE (0.1-12.8 $\mu \mathrm{g} / \mathrm{kg})$ produced dose-dependent increases and decreases in MAP and HR, respectively, and injections of SNP (6.4 and $51.2 \mu \mathrm{g} / \mathrm{kg}$ ) produced dose-dependent decreases and increases in MAP and HR, respectively. For example, PE increased MAP $(0.2 \mu \mathrm{g} / \mathrm{kg}: \Delta=5.5 \pm 1 ; 1.6 \mu \mathrm{g} / \mathrm{kg}: 27.5 \pm 1.5$; $25.6 \mu \mathrm{g} / \mathrm{kg}$ : $58.8 \pm 0.9 \mathrm{mmHg}, \mathrm{p}<0.001$ ) (Fig. $4 \mathrm{~A}$ and $\mathrm{C}$ ) and decreased HR $(0.2 \mu \mathrm{g} / \mathrm{kg}: \Delta=-10.8 \pm 0.6 ; 1.6 \mu \mathrm{g} / \mathrm{kg}:-34.5 \pm 0.7$; $25.6 \mu \mathrm{g} / \mathrm{kg}:-148.5 \pm 9.9 \mathrm{bpm}, \mathrm{p}<0.001$ ) (Fig. $4 \mathrm{~A}$ and D). In contrast, SNP decreased MAP $(0.2 \mu \mathrm{g} / \mathrm{kg}: \Delta=-4.5 \pm 0.9 ; 1.6 \mu \mathrm{g} / \mathrm{kg}$ : $-21.8 \pm 1 ; 51.2 \mu \mathrm{g} / \mathrm{kg}:-43 \pm 4 \mathrm{mmHg}, \mathrm{p}<0.001$ ) (Fig. $4 \mathrm{~B}$ and $\mathrm{E}$ ) and increased $\mathrm{HR}(0.2 \mu \mathrm{g} / \mathrm{kg}: \Delta=14 \pm 8 ; 1.6 \mu \mathrm{g} / \mathrm{kg}: 41 \pm 14$; $51.2 \mu \mathrm{g} / \mathrm{kg}: 121.3 \pm 15.2 \mathrm{bpm}, \mathrm{p}<0.001$ ) (Fig. $4 \mathrm{~B}$ and F). In the 6OHDA group, dose-dependent effects were observed only for the effects of PE on the MAP. Specifically, PE increased MAP $(0.2 \mu \mathrm{g} /$ kg: $\quad \Delta=12 \pm 2.7 ; \quad 6.4 \mu \mathrm{g} / \mathrm{kg}: \quad 59.3 \pm 8.5 ; \quad 25.6 \mu \mathrm{g} / \mathrm{kg}$ : $75.5 \pm 2.9 \mathrm{mmHg}, \mathrm{p}<0.001$ ) (Fig. $4 \mathrm{~A}$ and $\mathrm{C}$ ). These same doses were not able to decrease HR in a dose-dependent manner $(0.2 \mu \mathrm{g} / \mathrm{kg}$ : $\Delta=-11.5 \pm 4.9 ; \quad 6.4 \mu \mathrm{g} / \mathrm{kg}: \quad-45.3 \pm 5.1 ; \quad 25.6 \mu \mathrm{g} / \mathrm{kg}$ : $-62 \pm 6.1 \mathrm{bpm}, \mathrm{p}>0.05$ ) (Fig. 4A and D).

We observed similar increases in MAP in the 6-OHDA and vehicle groups $(\Delta=7 \pm 2.6$ to $66.5 \pm 6.1$, vs. vehicle: $7.3 \pm 0.5$ to $60.3 \pm 1.6 \mathrm{mmHg}, \mathrm{p}>0.05$; Fig. $4 \mathrm{~A}$ and $\mathrm{C}$ ). The highest dose of $\mathrm{PE}$ $(25.6 \mu \mathrm{g} / \mathrm{kg})$ produced a higher increase in MAP in 6-OHDA compared to the vehicle group $(\Delta=75.5 \pm 2.9$, vs. vehicle: $58.8 \pm 0.9 \mathrm{mmHg}, \mathrm{p}<0.001)$. However, bradycardia was blunted in 6-OHDA-lesioned rats with the three highest doses of PE $(\Delta=-45.5 \pm 5$ to $-62 \pm 6.0$, vs. vehicle: $-119.7 \pm 10$ to $-148.5 \pm 9.8$ bpm, $\mathrm{p}<0.001$; Fig. 4 A and D).

In 6-OHDA-lesioned rats, IV injection of SNP $(6.4$ and $51.2 \mu \mathrm{g} /$ $\mathrm{kg})$ produced a smaller decrease in MAP $(\Delta=-18.5 \pm 3$ and $-24.3 \pm 0.8$ vs. vehicle: $-30.5 \pm 1.9$ to $-43.5 \pm 3.9 \mathrm{mmHg}$, $\mathrm{p}<0.01$; Fig. $4 \mathrm{~B}$ and $\mathrm{E}$ ), and a smaller increase in HR was observed in response to doses of $1.6-51.2 \mu \mathrm{g} / \mathrm{kg}(\Delta=15.8 \pm 5$ to $49.5 \pm 13.6$ vs. vehicle: $41 \pm 14$ to $121.3 \pm 15.2 \mathrm{bpm}, \mathrm{p}<0.05$; Fig. $4 \mathrm{~B}$ and F).

Fig. 5A-B show the baroreflex sensitivity in response to PE and SNP injections based on analysis of the slope of the curves. Reflex bradycardia in response to the PE-induced increase in MAP was reduced in the 6 -OHDA group $(-0.794 \pm 0.159$, vs. vehicle: $-2.053 \pm 0.307 \mathrm{bpm} / \mathrm{mmHg}, \mathrm{p}<0.05)$, whereas the reflex tachycardia in response to the SNP-induced fall in MAP was similar between the 6-OHDA and control groups $(-2.37 \pm 0.099$, vs. vehicle: $-3.034 \pm 0.655 \mathrm{bpm} / \mathrm{mmHg}, \mathrm{p}>0.05$ ) (Fig. $5 \mathrm{~A}-\mathrm{B}$ ).

\subsection{Intrastriatal injection of 6-OHDA does not change the vasoconstrictor effect of PE in denuded mesenteric arteries of rats}

PE $(10 \mathrm{nmol} / \mathrm{L}$ to $0.1 \mathrm{mmol} / \mathrm{L})$ induced a concentrationdependent constrictor effect in resistance mesenteric arteries in both the control and 6-OHDA-injected groups (Fig. 6A). The efficacy of PE was similar between denuded (Fig. 6A) mesenteric arteries (E-) of the 6-OHDA and control groups (Maximum effect (ME): $21.63 \pm 3.97$ vs. vehicle: $20.30 \pm 3.18 \%, \mathrm{~N}=5$ artery rings $/ 5$ ani- 


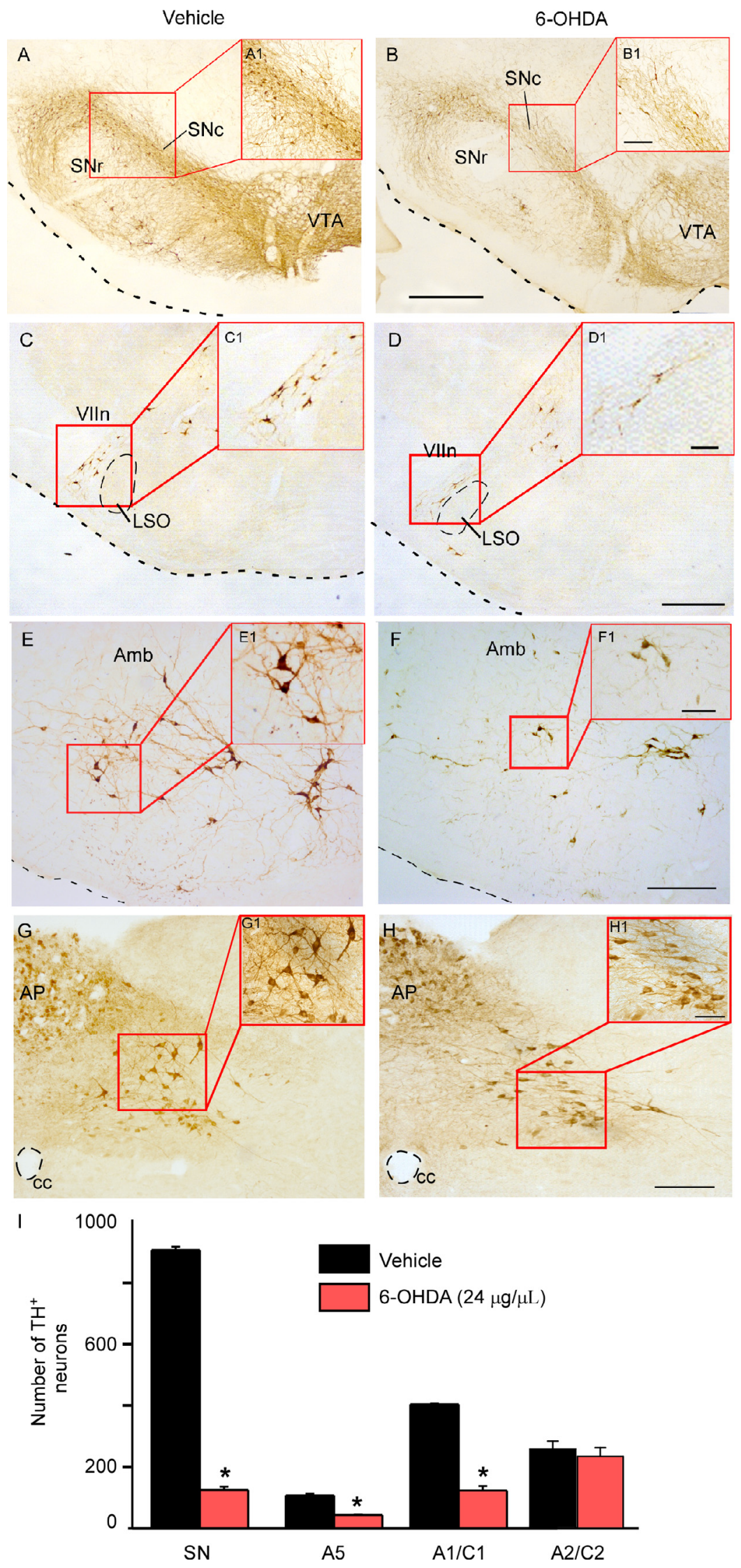


Vehicle
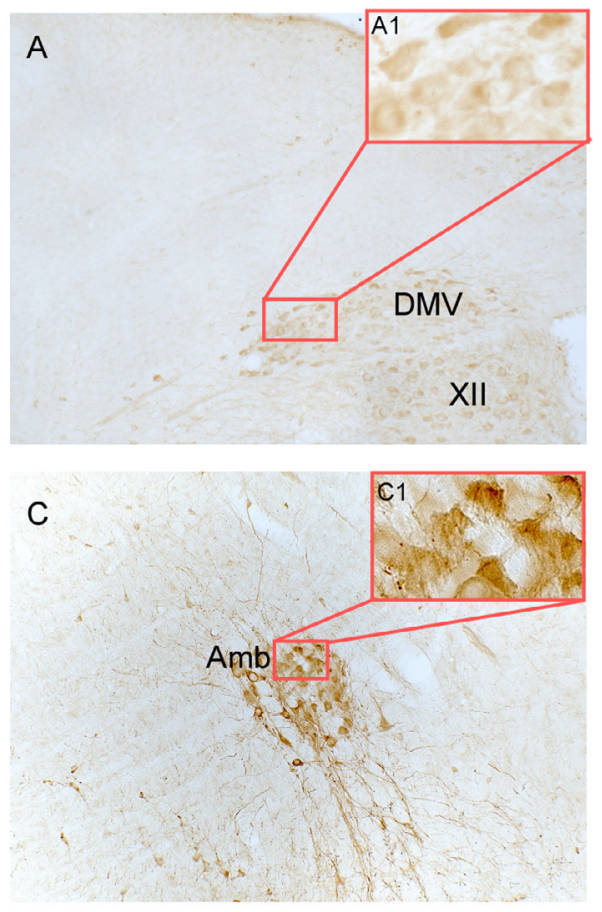

E
Vehicle

6-OHDA $(24 \mu \mathrm{g} / \mu \mathrm{L})$

\section{6-OHDA}
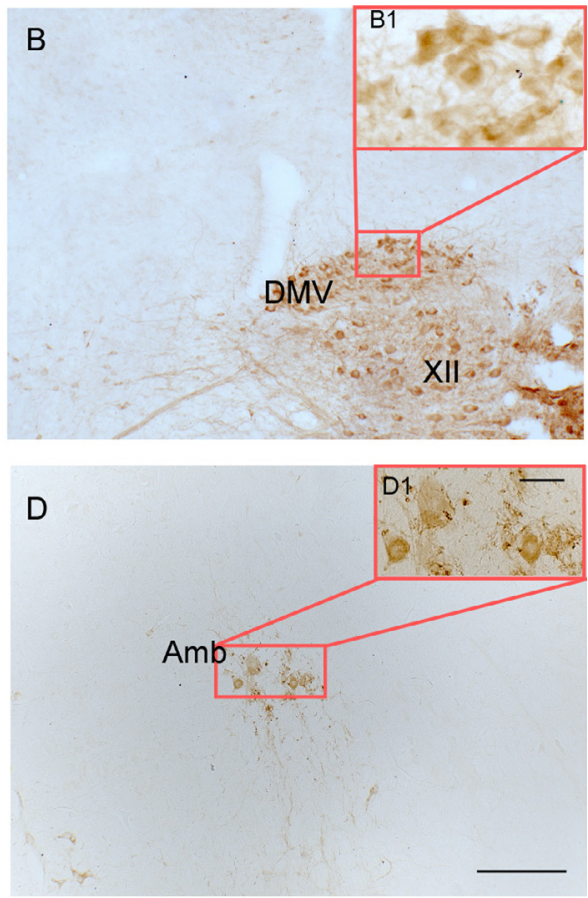
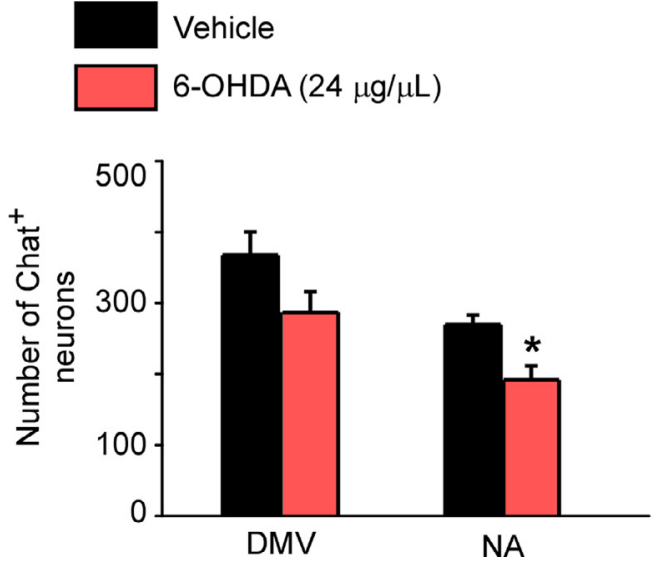

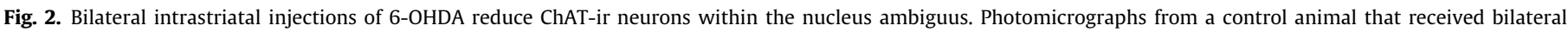

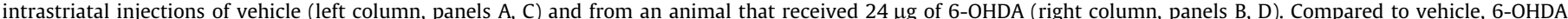

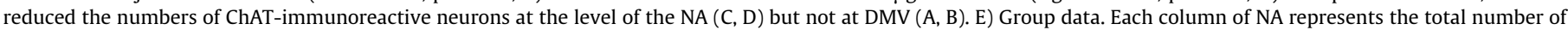

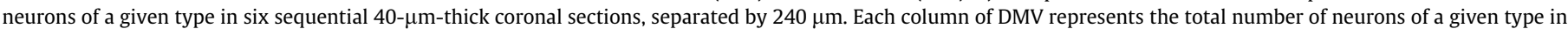

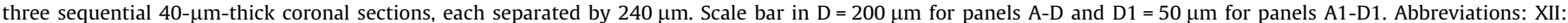
hypoglossal motor nucleus, DMV: dorsal motor vagus nucleus, Amb: nucleus ambiguus. " p $<0.05$ relative to vehicle. $\mathrm{N}=5$ per group.

mals/group; $\mathrm{p}>0.05)$. The potency of PE in denuded mesenteric arteries was similar between the 6-OHDA and control groups (pD2: $5.69 \pm 0.21$ vs. vehicle: $5.75 \pm 0.13, N=5$ artery rings $/ 5$ animals/group, p > 0.05; Fig. 6A).

\subsection{Intrastriatal injection of 6-OHDA impaired the relaxation to SNP and acetylcholine $(A C h)$ in resistance mesenteric arteries}

SNP $(0.1 \mathrm{nmol} / \mathrm{L}$ to $0.1 \mathrm{mmol} / \mathrm{L})$ induced a concentrationdependent dilator effect in denuded resistance mesenteric rings

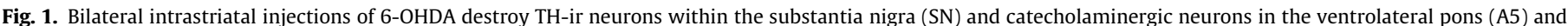

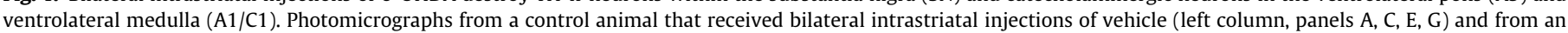

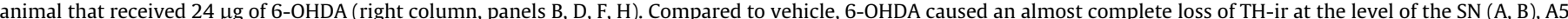

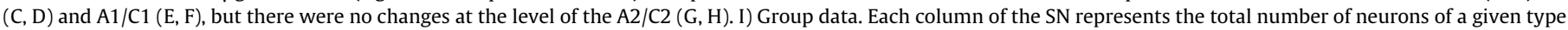

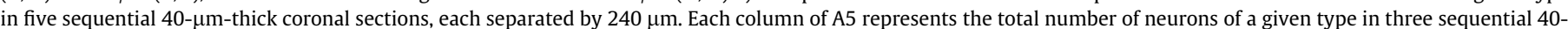

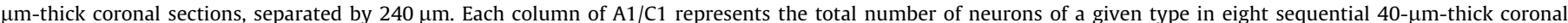

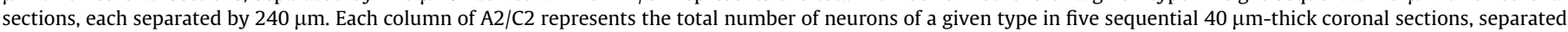

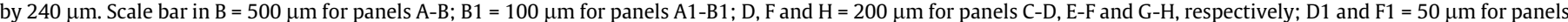

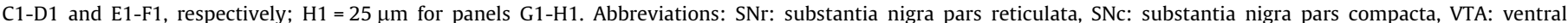

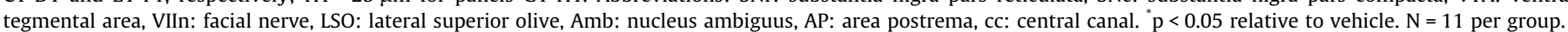



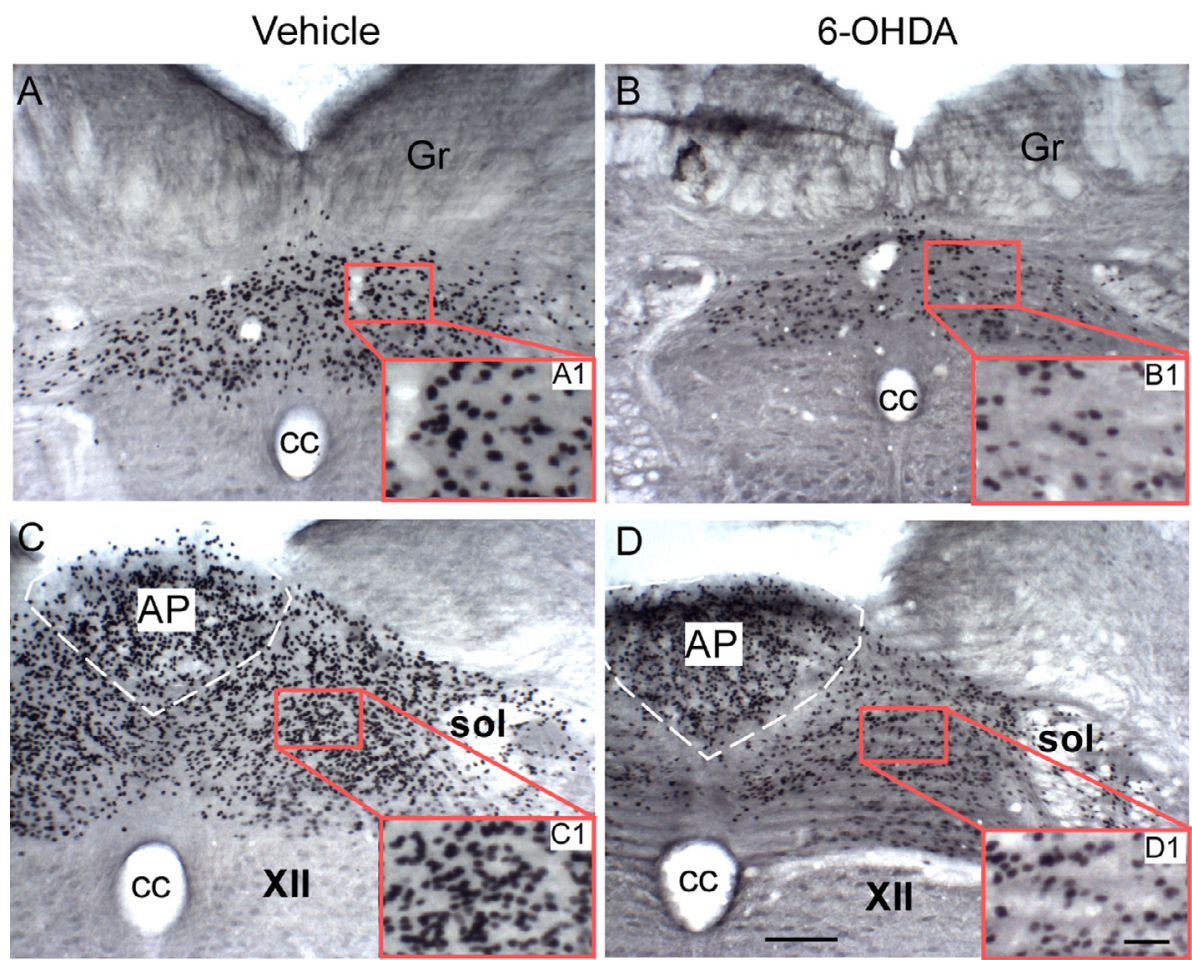

$E$

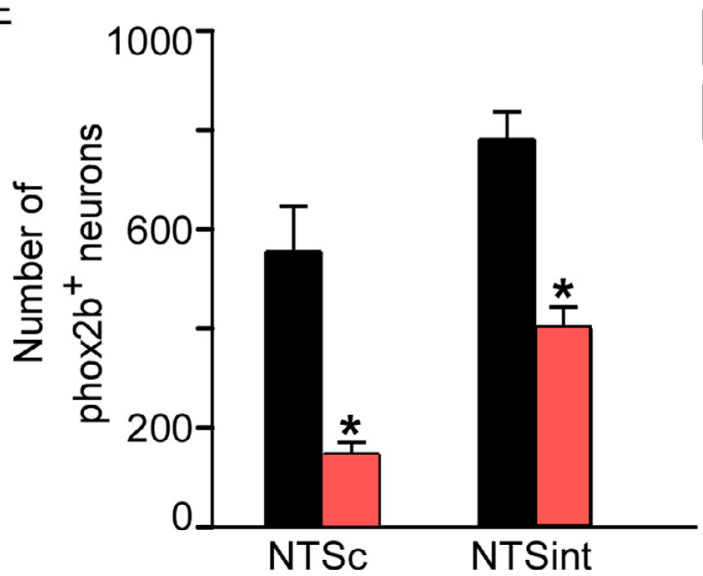

Vehicle 6-OHDA $(24 \mu \mathrm{g} / \mu \mathrm{L})$

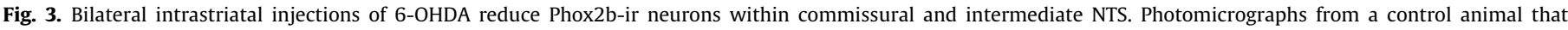

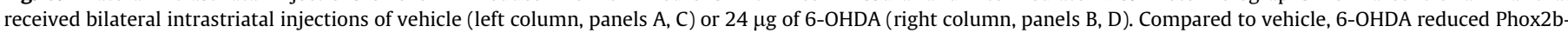

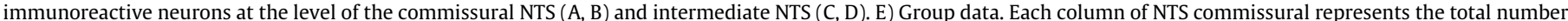

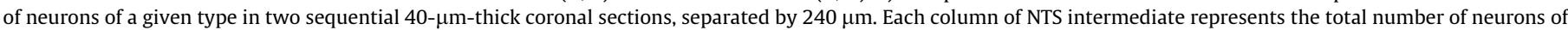

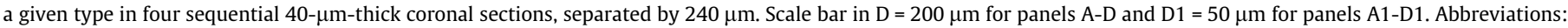
cc: central canal, Gr: nucleus gracilis, AP: area postrema, XII: hypoglossal motor nucleus, sol: solitary tract. " $\mathrm{p}<0.05$ relative to vehicle. $\mathrm{N}=6$ per group.

in both groups (Fig. 6B). The efficacy of SNP on the E-mesenteric arteries was similar between the 6-OHDA and control groups (ME: $89.04 \pm 3.26$ vs. vehicle: $94.41 \pm 1.81 \%, p>0.05$ ) (Fig. $6 B$ ). In denuded arteries, the potency of SNP was decreased in 6-OHDA rats compared to the control group (pD2: $6.13 \pm 0.10$, vs. vehicle: $7.22 \pm 0.11, \mathrm{p}<0.001$; Fig. $6 \mathrm{~B})$.

The maximum effect of ACh $(0.1 \mathrm{nmol} / \mathrm{L}$ to $0.1 \mathrm{mmol} / \mathrm{L})$ as seen in the concentration-effect curves (Fig. 6C) was similar in arteries of the two groups (ME: $95.42 \pm 0.94$ vs. vehicle: $93.93 \pm 0.91 \%$, $\mathrm{p}>0.05$ ). ACh potency in intact mesenteric resistance arteries ( $\mathrm{E}$ + ) was lower in 6-OHDA rats than in vehicle-injected rats (pD2: $5.82 \pm 0.10$ vs. vehicle: $7.44 \pm 0.09, \mathrm{p}<0.001$; Fig. $6 \mathrm{C}$ ).

\section{Discussion}

The current study reveals cardiovascular autonomic deficits after degeneration of dopaminergic neurons in the SN. We suggest that the 6-OHDA model of PD produces a dysfunction in baroreflex sensitivity and considerable changes in neuronal cytoarchitecture in the brainstem regions involved in the regulation of circulation.

Approximately $30-40 \%$ of PD patients have orthostatic hypotension $(\mathrm{OH})$ (Goldstein, 2003; Velseboer et al., 2011), a key manifestation of cardiovascular dysautonomia. One of the pathophysiological mechanisms underlying the cardiovascular autonomic abnormalities of $\mathrm{PD}$ is arterial baroreflex failure due to 
A
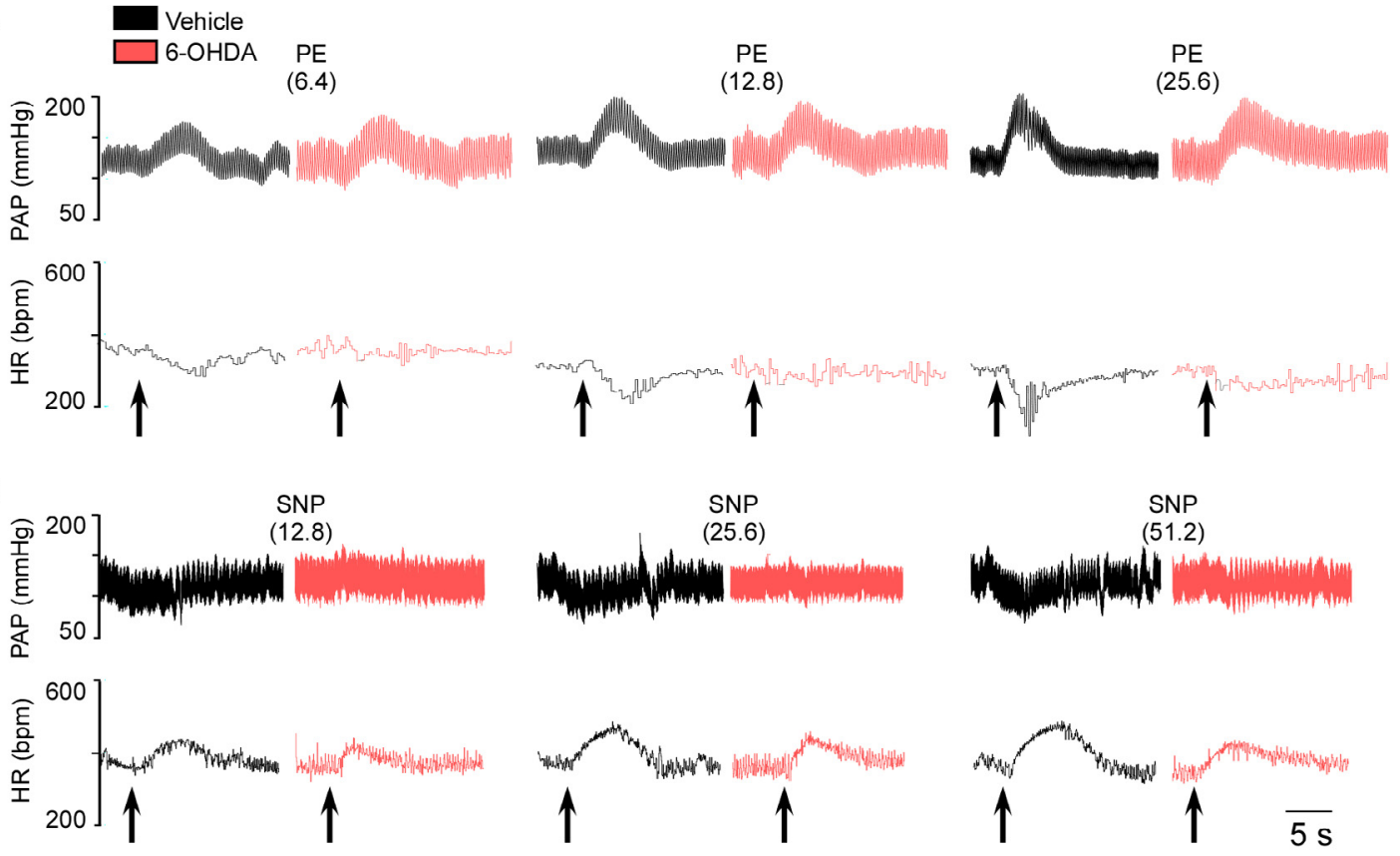

C

PE

E

SNP
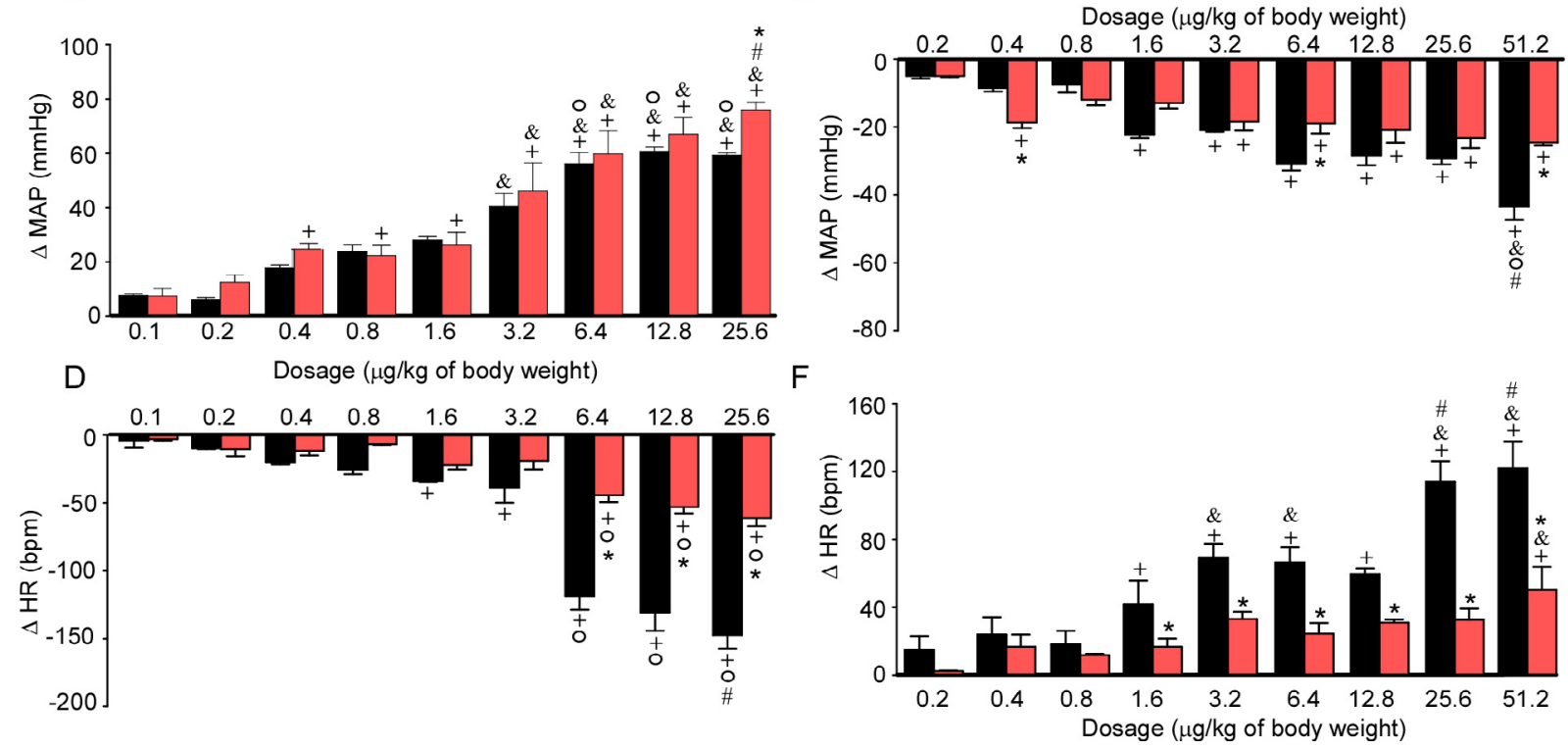

Fig. 4. 6-OHDA affected the cardiac baroreflex. Typical recordings showing changes in pulsatile arterial pressure (PAP) and heart rate (HR) produced by IV injection of the three highest doses tested of A) phenylephrine (PE: $6.4,12.8$ and $25.6 \mu \mathrm{g} / \mathrm{kg}$ of body weight) and B) sodium nitroprusside (SNP: $12.8,25.6$ and $51.2 \mu \mathrm{g} / \mathrm{kg}$ of body weight) in vehicle and 6-OHDA-lesioned rats. Arrows indicate the moment of the injection. Changes in mean arterial pressure ( $\Delta$ MAP) and HR ( $\Delta$ HR) produced by C-D) PE (0.1, 0.2, 0.4, $0.8,1.6,3.2,6.4,12.8$, and $25.6 \mu \mathrm{g} / \mathrm{kg}$ of body weight, IV) and E-F) SNP $(0.2,0.4,0.8,1.6,3.2,6.4,12.8,25.6$, and $51.2 \mu \mathrm{g} / \mathrm{kg}$ of body weight, IV) at 61 days after bilateral intrastriatal 6-OHDA $(24 \mu \mathrm{g})$ or vehicle. Significant differences between doses in the same group: $+\mathrm{p}<0.05$ relative to $0.1 \mu \mathrm{g} / \mathrm{kg}$ (PE) and $0.2 \mu \mathrm{g} / \mathrm{kg}$ (SNP); \& p $<0.05$ relative to $1.6 \mu \mathrm{g} / \mathrm{kg}$ (PE and SNP); o p < 0.05 relative to $3.2 \mu \mathrm{g} / \mathrm{kg}$ (PE and SNP); \# p < 0.05 relative to $6.4 \mu \mathrm{g} / \mathrm{kg}$ (PE and SNP). Significant differences between groups in the same dose: $\mathrm{p}<0.05$ relative to vehicle into the striatum (group effects). $\mathrm{N}=6 /$ group.

decreased function of both the parasympathetic and sympathetic components. Conflicting reports propose the possibility that medullary neuronal loss may underlie these autonomic dysfunctions in patients with PD (Benarroch et al., 2000; Gai et al., 1993; Saper et al., 1991). However, those studies analyzed only the catecholaminergic neurons of the $\mathrm{C} 1$ region.

Our study is the first to show that functional deficits in this model can be associated with specific neuroanatomical changes in key regions involved in neural control of circulation, i.e., A1/ C1, NTS, NA and A5.

\section{Cardiovascular deficits and Parkinsonism}

Our results show that the bilateral intrastriatal 6-OHDA model of PD has a significant reduction in the number of neurons in regions involved in baroreflex control, such as the NTS, NA and the catecholaminergic neurons within the $\mathrm{A} 1 / \mathrm{C} 1$ and $\mathrm{A} 5$ regions. For several reasons, the decreases in the catecholaminergic neurons of the $\mathrm{A} 1 / \mathrm{C} 1$ and $\mathrm{A} 5$ regions are probably not due to catecholaminergic or non-catecholaminergic neurons in different brain areas coming into contact with 6-OHDA by the diffusion of 

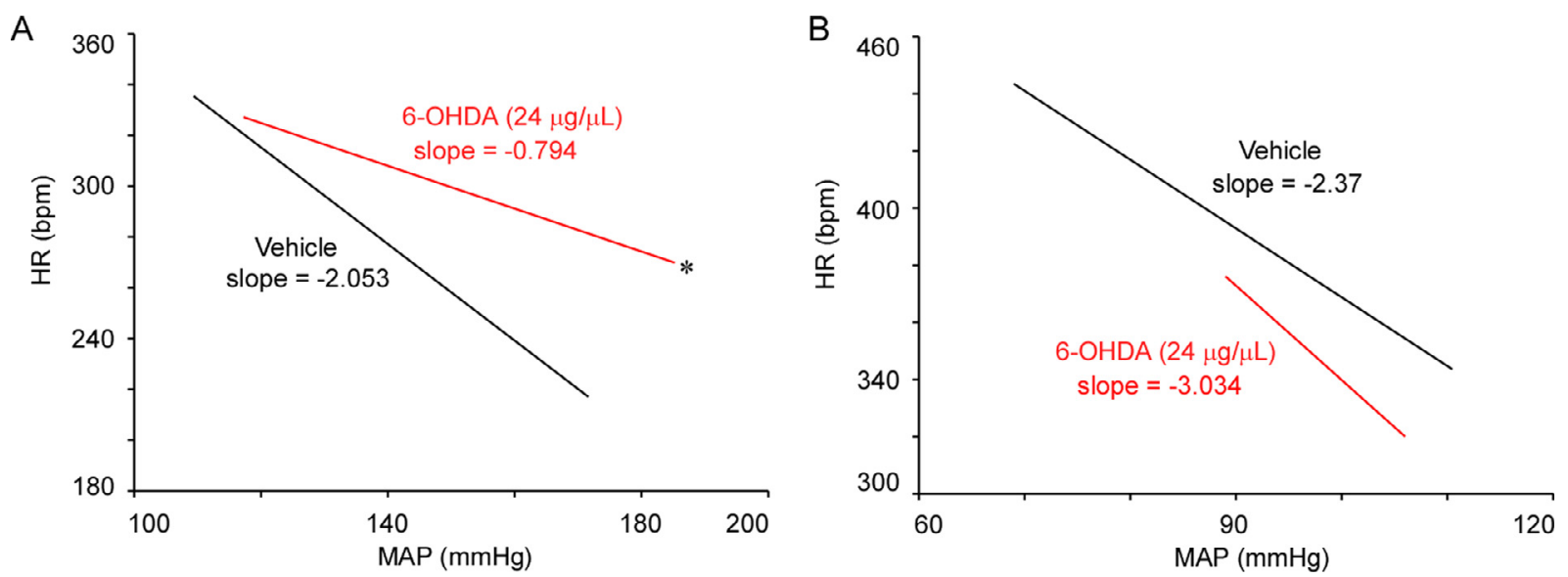

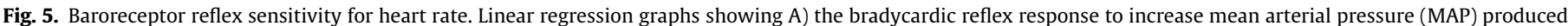

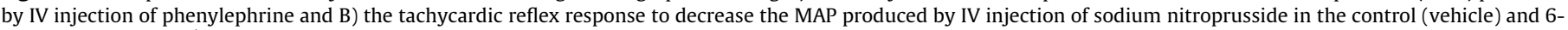
OHDA-lesioned rats. " $\mathrm{p}<0.05$ relative to vehicle into the striatum (Student's $t$-test).

the toxin through the ventricular system. i) PhenylethanolamineN-methyltransferase neurons are resistant to 6-OHDA (Fety et al., 1984); ii) using the same concentration and methodology as in the present study, a previous study from our laboratory showed that there is no reduction in the number of neurons showing $\mathrm{TH}-$ ir in the A6 region (Tuppy et al., 2015); iii) in a previous study, we did not observe a reduction in the density of neurokinin-1 receptors in the Bötzinger complex and the caudal ventral respiratory group (an important cluster of neurons involved in breathing activity) (Tuppy et al., 2015); iv) here, we did not observe a change in the number of neurons showing ChAT-ir in the DMV or TH-ir in the $\mathrm{A} 2 / \mathrm{C} 2$.

As expected, we observed that phenylephrine elicited a dosedependent pressor response, and the magnitude of the increase in blood pressure was similar between the two groups (control and 6-OHDA) except with the highest dose used, suggesting that there was no change in the vascular function mediated by adrenergic receptors. The bradycardic reflex to baroreceptor activation was milder in the 6-OHDA group, even with the highest dose, which produced a higher increase in blood pressure. This suggests a bradycardic impairment that is potentially associated with the reduction in parasympathetic activity (Goldstein, 2003). The reduction in parasympathetic activity observed in the 6-OHDA group may be associated with the observed reduction in the numbers of neurons showing Phox2b-ir in the NTS and ChAT-ir in the NA. The first central relay of the baroreflex consists of glutamatergic neurons located in the NTS, which receives monosynaptic inputs from baroreceptor afferents and projects to parasympathetic nuclei and to inhibitory neurons of the caudal ventrolateral medulla (CVLM) that in turn modulate the activity of presympathetic neurons in the C1 region (Guyenet, 2006). Additionally, previous studies have reported that neurons showing Phox2b-ir in the NTS are exclusively glutamatergic (Kang et al., 2007), that in Phox2b-null mutants, parasympathetic ganglia never form (Pattyn et al., 1999), and that neurons with Phox2b-ir in the NTS are involved in the baroreflex (Kang et al., 2007). Previous experiments have shown that $70 \%$ of NTS neurons activated by phenylephrine also contain Phox2b-ir. However, those experiments were not able to demonstrate whether Phox $2 \mathrm{~b}$-expressing neurons of the NTS project to parasympathetic nuclei or to CVLM inhibitory neurons (Kang et al., 2007).

Considering that small-diameter blood vessels are associated with vascular resistance and the maintenance of blood pressure, we calculated the concentration-effect curve to phenylephrine in denuded rings of the second and third branches of mesenteric arteries, and we observed that the potency and maximum effect of phenylephrine were similar between groups, suggesting that 6-OHDA treatment did not change the function of alphaadrenergic receptors in the vascular smooth muscle.

SNP is a potent vasodilator of arteries and veins. Its metabolization by red blood cells results in the release of nitric oxide (NO) (AlSa'doni and Ferro, 2000; Bogusz et al., 1979; Robin and McCauley, 1992). Here, we showed that the hypotension, tachycardia and vascular reactivity in response to SNP were reduced in the 6-OHDA group. However, no changes in the baroreflex sensitivity were observed. Similarly, a previous study demonstrated that the integrity of $\mathrm{C} 1$ cells is not essential for the maintenance of resting blood pressure but is crucial for the tachycardia response evoked by baroreflex deactivation (Schreihofer and Guyenet, 2000).

We also observed a reduction in the number of catecholaminergic neurons in the A5 region. Located in the ventrolateral pons, the A5 region has spinal projections exclusively targeting the intermediolateral cell group (Loewy et al., 1979), and these projections are proposed to regulate sympathetic nerve activity and blood pressure (Koshiya and Guyenet, 1994). Evidence from the literature suggests that A5 neurons are under baroreceptor control (Huangfu et al., 1991). Additionally, A5 neurons receive inputs from $\mathrm{C} 1$ neurons, suggesting that the $\mathrm{C} 1$ region may represent a potential source of excitatory drive to the A5 region. In our model, both regions contain a reduced number of neurons, which may explain an impairment of the baroreflex control.

We cannot exclude the contribution of the inhibition of sympathetic and parasympathetic tone to the changes in heart rate during baroreflex activation and deactivation, respectively. However, our results show that in the 6-OHDA group, although there is also a reduction in $\mathrm{C} 1$ neurons, this reduction seems to be insufficient to produce bradycardia during activation of the baroreflex. Similarly, evaluating the deactivation of the baroreflex, we observed a reduction in the number of NA neurons that could produce a tachycardic response. In the former case, we must also consider that SNP in 6-OHDA animals was not able to produce a hypotensive response similar to that in control animals; that lack of response might also be a reason for the observed reduction in the tachycardic response.

A previous study reported an impairment in autonomic modulation in the same model used in the present study (Ariza et al., 2015). However, properly interpreting these results requires the consideration of several important issues. Here, we performed 
A

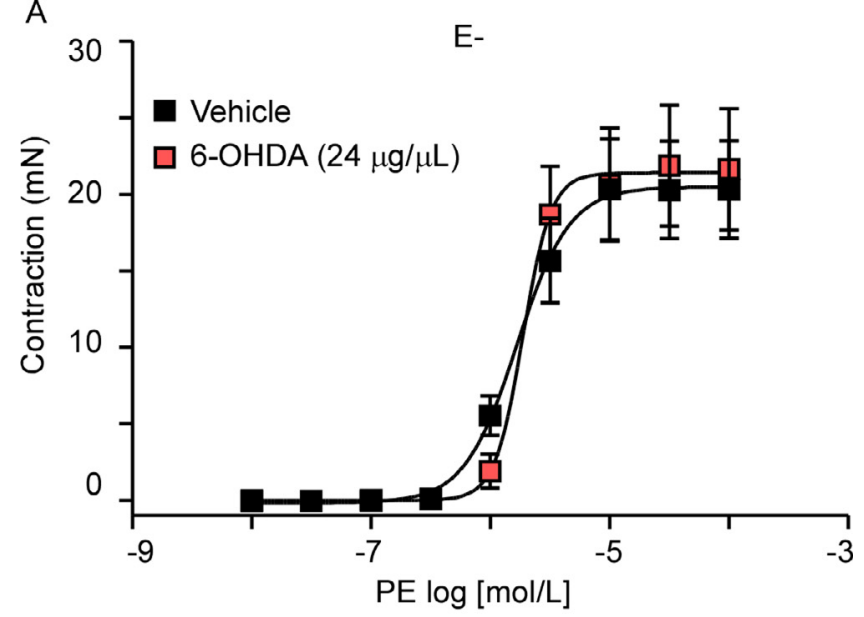

B

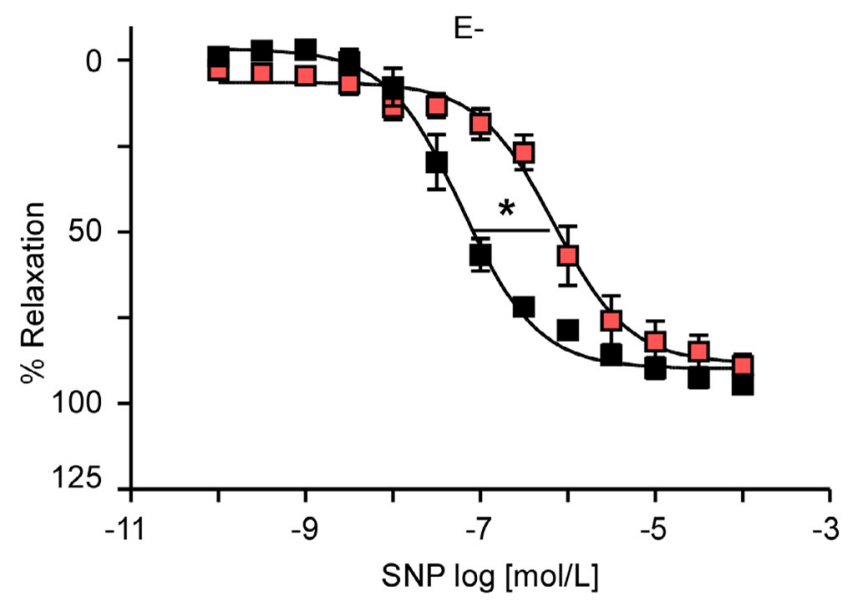

C

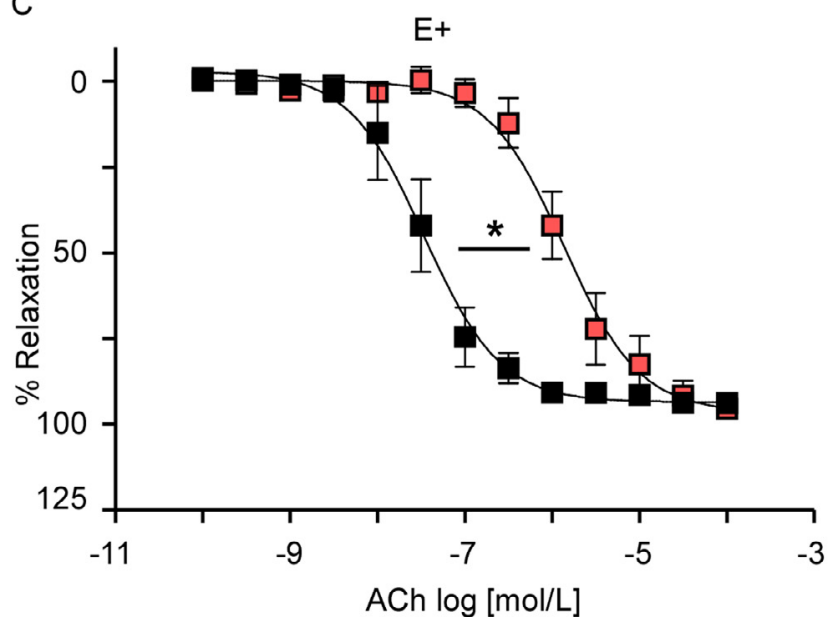

Fig. 6. 6-OHDA impaired the reactivity of the resistance arteries to PE, ACh and SNP. Concentration-response curves to A) phenylephrine (PE, $10 \mathrm{nM}-100 \mu \mathrm{M})$ in denuded (E-), B) to sodium nitroprusside (SNP, $0.1 \mathrm{nM}-100 \mu \mathrm{M}$ ) in $\mathrm{E}-$ and $\mathrm{C}$ ) to acetylcholine (ACh, $0.1 \mathrm{nM}-100 \mu \mathrm{M}$ ) in intact $(\mathrm{E}+)$ mesenteric resistance arteries of rats injected with 6 -OHDA $(24 \mu \mathrm{g})$ or vehicle. Data are reported as the mean \pm SEM. $\mathrm{p}<0.05$ relative to vehicle into striatum. $\mathrm{N}=5$ artery rings for each treatment from each of 5 animals per group.

experiments 61 days after 6-OHDA injection into the striatum, while the experiments in the previous study were performed only 7 days after the lesion. An ideal model of PD should exhibit pathological and clinical features that mimic the human disease, including motor and non-motor symptoms, as well as the progressive degenerative nature of $\mathrm{PD}$. The former study used the model in which 6-OHDA was injected directly into the SN and performed the functional analysis only 7 days post-injection, which is insufficient time to create a reliable lesion of the nigrostriatal pathway, a key characteristic of PD (Jeon et al., 1995). We used a progressive degeneration of dopaminergic neurons of the striatum, i.e., the experiments were performed 61 days after the lesion. In our model, we did not observe classic motor symptoms, but we observed a reduction in the baseline breathing (Tuppy et al., 2015) and a cardiovascular imbalance (present results). Additionally, we did not observe changes in baseline blood pressure or heart rate, while the previous study reported considerable reductions in these cardiovascular parameters. This effect may be attributable the fact that the dopaminergic terminals in the striatum are still releasing dopamine at 7 days post-lesion. Dopamine can have an inhibitory effect on the cardiovascular system, leading to a depression of cardiovascular parameters (Hassan et al., 2015; Niewinski et al., 2014; Oliva et al., 2010). Importantly, the present results are the first to address a correlation between functional and specific neuroanatomical changes that can contribute to the dysautonomia observed in this model of PD.

The former study suggested that in the 6-OHDA animal model of PD, there is lower sympathetic modulation of the vasculature and no changes in the parasympathetic activity. Our results are in agreement only because we observed a massive reduction in the number of presympathetic neurons in the A1/C1 region. However, the bradycardic response to baroreceptor activation is mediated by the parasympathetic system, and our data showed significant reductions in the number of NA neurons and in the bradycardic response to phenylephrine. These differences may explain some of the discrepancies observed between the current work and the previous study (Ariza et al., 2015).

\section{Conclusion}

Our results showed that the bilateral intrastriatal 6-OHDA model of PD led to a massive degeneration of neurons with TH-ir in the SN, and this was associated with significant decreases in Phox2b-ir in the NTS, ChAT-ir in the NA and TH-expressing neurons in the $\mathrm{A} 1 / \mathrm{C} 1$ and $\mathrm{A} 5$ regions. We also observed that other brainstem regions involved in neural control of blood pressure, such as ChAT-ir in the DMV and TH-ir in A2/C2, were not affected in this model. Our conclusion is that those specific neuroanatomical changes may be associated with a deficit in the bradycardic response to baroreflex activation, a non-motor symptom of PD. Moreover, our data suggest that the 6-OHDA PD model may also blunt the response of mesenteric artery resistance. Those results may contribute to future studies trying to elucidate the mechanisms involved in cardiovascular dysfunction in this model.

\section{Methods and materials}

\subsection{Animals}

Experiments were performed in 22 adult male Wistar rats (250-350 g), and the entire protocol lasted two months. Animals were used in accordance with the guidelines of the Animal Experimentation Ethics Committee of the Institute of Biomedical Sciences at the University of São Paulo (ICB/USP) and the NIH.

\subsection{6-OHDA injection}

The bilateral injection of 6-OHDA hydrochloride (6-OHDA hydrochloride, H4381, Sigma, Saint Louis, MO, USA) into the striatum was performed acutely as previously described (Tuppy et al., 
2015). Briefly, the animals were anesthetized with a mixture of ketamine $(80 \mathrm{mg} / \mathrm{kg})$ and xylazine $(7 \mathrm{mg} / \mathrm{kg})$ intraperitoneally (IP) and placed in a stereotaxic frame (model 900; David Kopf Instruments) to receive two injections of 6-OHDA $(24 \mu \mathrm{g} / \mu \mathrm{L}$ in $0.3 \%$ ascorbic acid saline solution) or vehicle $(0.3 \%$ ascorbic acid) in the dorsal striatum using a $10 \mu \mathrm{L}$ Hamilton syringe and the following coordinates: 1) $0.0 \mathrm{~mm}$ caudal to bregma, $\pm 2.7 \mathrm{~mm}$ lateral to the midline, $4.5 \mathrm{~mm}$ ventral to the dorsal surface of the brain and 2) $0.5 \mathrm{~mm}$ caudal to bregma, $\pm 3.2 \mathrm{~mm}$ lateral to midline, $4.5 \mathrm{~mm}$ ventral to the dorsal surface of the brain. The volume of the injection was $0.5 \mu \mathrm{L} / \mathrm{site}$. After the 6-OHDA injection, the animals were allowed to survive for 60-61 days until vascular cannulation or vascular reactivity experiments.

\subsection{In vivo experiments}

\subsubsection{Baroreflex analysis}

Pulsatile arterial pressure (PAP), mean arterial pressure (MAP) and heart rate (HR) were recorded in unanesthetized, freely moving rats as previously described (Favero et al., 2011; Takakura et al., 2014; Barna et al., 2016). Briefly, one day before the experiments, under IP injection of ketamine combined with xylazine anesthesia, polyethylene tubing (PE-10 connected to PE-50; Clay Adams, Parsippany, NJ, USA) was inserted into the femoral vein and abdominal aorta through the femoral artery. The cannulas were tunneled subcutaneously to the animal's back to allow for measurement while they were freely moving. Water and food intake and motor activity were unchanged $24 \mathrm{~h}$ after cannulation. Although motor activity was not quantified, visual observation in their home cages and during handling revealed no apparent differences in reactivity or locomotion before and after cannulation.

The arterial catheter was connected to a pressure transducer (MLT844, ADInstruments, Sydney, NSW, Australia) coupled to a preamplifier (Bridge Amp, ML221, ADInstruments, Sydney, NSW, Australia) that was connected to a Powerlab computer data acquisition system (PowerLab 16/30, ML880, ADInstruments). A variable period of time (30-50 min) was allowed for the stabilization of cardiovascular parameters before beginning simultaneous measurement of PAP and HR. For baroreceptor stimulation, $100-\mu \mathrm{L}$ bolus injections of graded doses of phenylephrine (PE: $0.1 ; 0.2 ; 0.4$; $0.8 ; 1.6 ; 3.2 ; 6.4 ; 12.8$ and $25.6 \mu \mathrm{g} / \mathrm{kg}$ ) and sodium nitroprusside (SNP: $0.2 ; 0.4 ; 0.8 ; 1.6 ; 3.2 ; 6.4 ; 12.8 ; 25.6$ and $51.2 \mu \mathrm{g} / \mathrm{kg}$ ) were administered into the femoral vein. PE and SNP injections were made in a random order, and subsequent injections were not made until the recorded parameters had returned to baseline levels. Values of matching MAP variations with reflex HR response were separately plotted for each vasoactive drug to create linear regression curves of baroreceptor function for each group, and their slopes (beats $/ \mathrm{min} / \mathrm{mmHg}$ ) were compared to test changes in the baroreceptor reflex sensitivity.

\subsection{In vitro experiments}

\subsubsection{Vessel preparation}

The animals were anesthetized with halothane (Tanohalo ${ }^{\circledR}$, Cristália, Itapira, Brazil), euthanized by decapitation and exsanguinated. The mesenteric bed was removed and placed in a Petri plate containing cold Krebs-Henseleit buffer $\left(4^{\circ} \mathrm{C}\right)$ with the following composition (mmol/L): $\mathrm{NaCl} 130.00 ; \mathrm{NaHCO}_{3} 14.9 ; \mathrm{C}_{6} \mathrm{H}_{12} \mathrm{O}_{6}$ 5.5; $\mathrm{KCl}$ 4.7; $\mathrm{KH}_{2} \mathrm{PO}_{4}$ 1.18; $\mathrm{MgSO}_{4}$ 1.17; $\mathrm{CaCl}_{2}$ 1.6; $\mathrm{pH}$ 7.4. The mesenteric artery was cleaned of connective tissue under a dissection stereomicroscope (Luxeo 2S, Labomed, Los Angeles, USA).

\subsubsection{Vascular reactivity}

The 2 nd or 3rd segments from the mesenteric artery were cut in rings $2-\mathrm{mm}$ in length and mounted in a small vessel dual-chamber myograph for isometric tension measurement. Two tungsten wires (40- $\mu$ m diameter) were introduced through the lumen of the rings and mounted according to the method described by Mulvany and Halpern (Halpern and Mulvany, 1977). In some rings, the endothelium was removed by gently rubbing the intimal surface with a human hair. After a 30 -min equilibration period in oxygenated Krebs solution at $37{ }^{\circ} \mathrm{C}$ and $\mathrm{pH} 7.4$, rings were stretched to their optimal lumen diameter for active tension development. The diameter was determined based on the internal circumference-wall tension ratio of the rings by setting their internal circumference (L0) to $90 \%$ of the circumference that the vessels would have if they were exposed to a passive tension that was equivalent to that produced by a transmural pressure of $100 \mathrm{mmHg}$ (Halpern and Mulvany, 1977). The effective lumen diameter was calculated as $L 0 / \pi$. Next, rings were washed three times with Krebs-Henseleit buffer and left to equilibrate for $30 \mathrm{~min}$. To test the viability of the preparations, rings were stimulated with a highconcentration solution of potassium $(120 \mathrm{mmol} / \mathrm{L}, 15 \mathrm{~min})$. Functionality of endothelial cells was verified by relaxation to acetylcholine (ACh: $10 \mu \mathrm{mol} / \mathrm{L}$ ), and efficient removal of endothelial cells was verified by the lack of relaxation to ACh $(10 \mu \mathrm{mol} / \mathrm{L})$ in rings pre-contracted with PE $(10 \mu \mathrm{mol} / \mathrm{L})$. Rings with more than $70 \%$ relaxation to acetylcholine were classified as rings with intact endothelium, and rings with less than $10 \%$ relaxation to acetylcholine were used in the experiments without endothelium. Endothelium releases vasodilator and vasoconstrictor factors. Then, to analyze the maximum response to PE or SNP, we used mesenteric artery rings without endothelium, since endothelium can modulate the responses to $\mathrm{PE}$ or SNP. Cumulative concentration-response curves to $\mathrm{ACh}(0.1 \mathrm{nmol} / \mathrm{L}$ to $0.1 \mathrm{mmol} / \mathrm{L})$ were performed in intact resistance mesenteric arteries; cumulative concentration-response curves to SNP $(0.1 \mathrm{nmol} / \mathrm{L}$ to $0.1 \mathrm{mmol} / \mathrm{L})$ and to $\mathrm{PE}(10 \mathrm{nmol} / \mathrm{L}$ to $0.1 \mathrm{mmol} / \mathrm{L})$ were performed in denuded resistance mesenteric arteries.

\subsubsection{Histology}

Rats were anesthetized (pentobarbital overdose, $60 \mathrm{mg} / \mathrm{kg}$, IP) and perfused transcardially, first with heparinized saline ( $300 \mathrm{~mL}$ ) and then with $4 \%$ phosphate-buffered paraformaldehyde (PFA, $500 \mathrm{~mL}$ ). Brains were removed and postfixed in PFA for 12 days at $4{ }^{\circ} \mathrm{C}$. Coronal sections $(40 \mu \mathrm{m})$ were cut using a vibrating microtome (Vibratome $1000 \mathrm{~s}$ ) and stored in cryoprotectant solution at $-20^{\circ} \mathrm{C}$ for up to two weeks until histological processing (Schreihofer and Guyenet, 1997).

All histological procedures were conducted with free-floating sections. No labeling was observed when the primary antibodies were omitted. Sections were rinsed, blocked and subjected to the immunoperoxidase method with specific antibodies. Tyrosine hydroxylase $(\mathrm{TH})$ is the rate-limiting enzyme responsible for the synthesis of dopamine, noradrenaline and adrenaline. Therefore, it was selected for labeling neurons of the SN (dopaminergic neurons), C1 and C2 (adrenergic neurons), and A1, A2 and A5 (noradrenergic neurons). Choline acetyltransferase (ChAT) is a transferase enzyme responsible for the synthesis of the neurotransmitter acetylcholine and was therefore used as a marker for preganglionic parasympathetic neurons in the NA and DMV. The paired-like homeobox gene Phox $2 b$ is expressed by central excitatory relays of the sympathetic baroreflex (NTS) and was used in this study as a marker for that nucleus (Stornetta et al., 2006; Barna et al., 2012; Tuppy et al., 2015). For TH and ChAT, color development was carried out using imidazole-diaminobenzidine (DAB), and for Phox $2 b$, the staining used was Nickel-Cobalt-DAB. All of the antibodies used in the present study were experimentally characterized as previously demonstrated (Barna et al., 2012; Pattyn et al., 1997; Stornetta et al., 2006). 


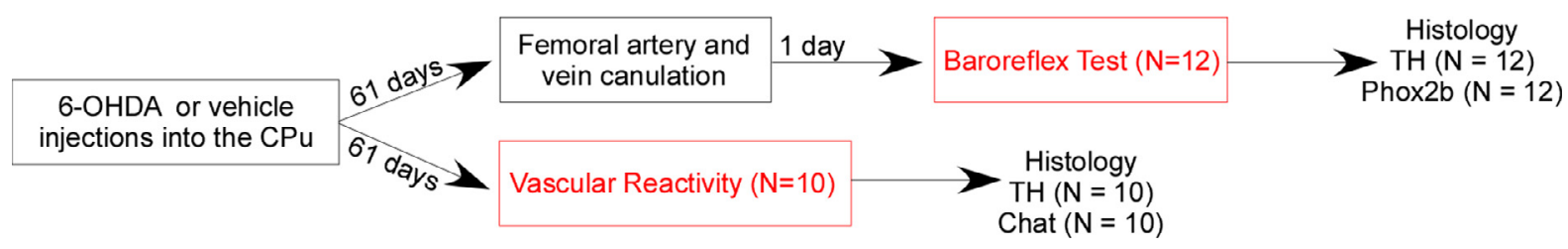

Fig. 7. Experimental design. Indicates the fraction of rats in which each of the anatomical and physiological experiments was performed.

\subsubsection{Cell mapping, cell counting and imaging}

A conventional multifunction microscope (brightfield, darkfield and epifluorescence; Zeiss Axioskop 2 (Oberkochen, Germany)) was used for all observations unless otherwise indicated. ImageJ software (public domain program available from the NIH; http// rsb.info.nih.gov/ij/) was used to count the various types of neuronal profiles within a defined area.

For each rat, every sixth $40-\mu \mathrm{m}$ brain section was used, which means that the sections analyzed were $240 \mu \mathrm{m}$ apart. The sections were counted bilaterally, and the numbers reported in the results section correspond exactly to the counts of every sixth section in the indicated series. Section alignment between brains was performed relative to a reference section, as previously described (Tuppy et al., 2015). Briefly, to align sections around the substantia nigra (SN) level, the most caudal section containing the medial geniculate nucleus was identified in each brain and assigned the level $6.04 \mathrm{~mm}$ caudal to Bregma (Bregma $=-6.04 \mathrm{~mm}$ ). To align sections around the nucleus of the solitary tract (NTS) level, the section containing the mid-area postrema was identified in each brain and assigned the level $13.8 \mathrm{~mm}$ caudal to Bregma (Breg$\mathrm{ma}=-13.8 \mathrm{~mm}$ ). Levels rostral or caudal to the reference section were determined by adding a distance corresponding to the interval between sections multiplied by the number of intervening sections. The same method was also used to identify the Bregma levels of the C1, A5, nucleus ambiguus (NA) and dorsal motor nucleus of vagus (DMV) areas. Analyses were performed using 6 sections of the NTS, 5 sections of the SN, 8 sections of the $A 1 / C 1,3$ sections of the $A 5,5$ sections of the $A 2 / C 2,6$ sections of the NA and 3 sections of the DMV.

All files were exported to the Canvas 9 drawing program for final modifications. Photographs were taken with a 12-bit color CCD camera (CoolSnap, Roper Scientific, Tucson, AZ; resolution $1392 \times 1042$ pixels).

The neuroanatomical nomenclature is in accordance with that described in Paxinos and Watson (1998).

\subsection{Statistical analysis}

Data were analyzed using unpaired Student's t-tests or twoway repeated measures ANOVA followed by Tukey or NewmanKeuls post hoc tests. All results are presented as the means \pm SEM. Differences were considered significant when $p<0.05$. The EC50 (concentration of the agent that produced half-maximal relaxation amplitude) was determined after logarithmic transformation of the normalized concentration-response curves and is reported as the negative logarithm (pD2). The maximum effect (ME) was considered the maximal amplitude of response reached in the concentration-response curves for PE, SNP or ACh.

\subsection{Experimental protocol}

Two injections of $0.5 \mu \mathrm{L} /$ site of 6 -OHDA $(24 \mu \mathrm{g} / \mu \mathrm{L})$ or saline $+0.3 \%$ ascorbic acid ( $\mathrm{N}=5$ animals/group for in vitro experiments and $\mathrm{N}=6$ animals/group for in vivo experiments) were performed bilaterally in the striatum (caudate-putamen) to induce a retrograde neuronal nigrostriatal injury (Blum et al., 2001). For in vivo experiments, sixty days after 6-OHDA, the femoral artery and vein were cannulated to evaluate the baroreflex, and the experiments were performed the following day. For in vitro experiments, sixty-one days after 6-OHDA, the animals were anesthetized to remove segments from the mesenteric artery for experiments. Three artery rings per animal were used to perform 3 different experiments (PE, SNP and $\mathrm{ACh}$ ). At the end of the in vivo experiments, all animals were sacrificed and perfused. The brains of all animals were removed for histological analysis. The animal and experimental protocols used are shown in schematic form in Fig. 7.

\section{Grants}

This research was supported by public funding from the Fundação de Amparo à Pesquisa do Estado de São Paulo (FAPESP) (grants: $14 / 22406-1$ to ACT; $12 / 20398-6$ to CA) and the Conselho Nacional de Desenvolvimento Científico e Tecnológico (CNPq) (grants: $471263 / 2013-3$ to ACT; 471283/2012-6 to TSM) and by funds from a FAPESP fellowship (2011/21841-8 to MT; 2015/11268-0 to BF) and a CNPq fellowship (305533/2012-6 to TSM and 301651/2013-2 to ACT).

\section{Author contributions}

TSM, CA and ACT designed the experiments; BF, MT, SRP and ACT collected and analyzed data; BF, MT, TSM, CA and ACT wrote the paper. All authors approved the final version of the manuscript.

\section{Conflict of interest statement}

We declare no conflict of interest.

\section{Acknowledgments}

We gratefully acknowledge J.F. Brunet (Departement de Biologie, EcoleNormaleSuperieure, Paris, France) for providing the Phox2b antibody, J.C. Callera (Department of Basic Sciences, School of Dentistry of Araçatuba, Araçatuba, Brazil) for the stereotaxic apparatus and Fabiane C. Fernandes for expert technical assistance. We would like to also acknowledge Dr. Lisete C. Michelini for helping with the baroreflex analysis.

\section{References}

Al-Sa'doni, H., Ferro, A., 2000. S-Nitrosothiols: a class of nitric oxide-donor drugs. Clin. Sci. (Lond) 98, 507-520.

Ariza, D., Lopes, F.N., Crestani, C.C., Martins-Pinge, M.C., 2015. Chemoreflex and baroreflex alterations in Parkinsonism induced by 6-OHDA in unanesthetized rats. Neurosci. Lett. 607, 77-82.

Barna, B.F., Takakura, A.C., Moreira, T.S., 2012. Pontomedullary and hypothalamic distribution of Fos-like immunoreactive neurons after acute exercise in rats. Neuroscience 212, 120-130.

Barna, B.F. Takakura, A.C., Mulkey, D.K., Moreira, T.S., 2016. Purinergic receptor blockade in the retrotrapezoid nucleus attenuates the respiratory chemoreflexes in awake rats. Acta Physiol. 217, 80-93.

Bassetti, C.L., 2011. Nonmotor disturbances in Parkinson's disease. Neurodegener. Dis. 8, 95-108.

Benarroch, E.E., Schmeichel, A.M., Parisi, J.E., 2000. Involvement of the ventrolateral medulla in parkinsonism with autonomic failure. Neurology 54, 963-968. 
Blum, D., Torch, S., Lambeng, N., Nissou, M., Benabid, A.L., Sadoul, R., Verna, J.M., 2001. Molecular pathways involved in the neurotoxicity of 6-OHDA, dopamine and MPTP: contribution to the apoptotic theory in Parkinson's disease. Prog. Neurobiol. 65, 135-172. ed.^eds., England.

Bogusz, M., Moroz, J., Karski, J., Gierz, J., Regieli, A., Witkowska, R., Golabek, 1979. Blood cyanide and thiocyanate concentrations after administration of sodium nitroprusside as hypotensive agent in neurosurgery. Clin. Chem. 25, 60-63.

Cai, G.J., Miao, C.Y., Xie, H.H., Lu, L.H., Su, D.F., 2005. Arterial baroreflex dysfunction promotes atherosclerosis in rats. Atherosclerosis 183, 41-47.

Chan, R.K., Sawchenko, P.E., 1994. Spatially and temporally differentiated patterns of c-fos expression in brainstem catecholaminergic cell groups induced by cardiovascular challenges in the rat. J. Comp. Neurol. 348, 433-460.

Chaudhuri, K.R., Odin, P., Antonini, A., Martinez-Martin, P., 2011. Parkinson's disease: the non-motor issues. Parkinsonism Relat. Disord. 17, 717-723.

Dickson, D.W., Fujishiro, H., Orr, C., DelleDonne, A., Josephs, K.A., Frigerio, R., Burnett, M., Parisi, J.E., Klos, K.J., Ahlskog, J.E., 2009. Neuropathology of non-motor features of Parkinson disease. Parkinsonism Relat. Disord. 15 (Suppl. 3), S1-S5.

Ergene, E., Dunbar, J.C., O’Leary, D.S., Barraco, R.A., 1994. Activation of P2purinoceptors in the nucleus tractus solitarius mediate depressor responses. Neurosci. Lett. 174, 188-192.

Favero, M.T., Takakura, A.C., de Paula, P.M., Colombari, E., Menani, J.V., Moreira, T.S., 2011. Chemosensory control by commissural nucleus of the solitary tract in rats. Respir. Physiol. Neurobiol. 179, 227-234.

Fearnley, J.M., Lees, A.J., 1991. Ageing and Parkinson's disease: substantia nigra regional selectivity. Brain 114 (Pt 5), 2283-2301.

Fety, R., Lambas-Senas, L., Chamba, G., Renaud, B., 1984. Changes in tyrosine hydroxylase and dopamine-beta-hydroxylase activities but not in phenylethanolamine-N-methyltransferase activity within central adrenaline neurons after 6-hydroxydopamine administration. Biochem. Pharmacol. 33, 1887-1891.

Gai, W.P., Geffen, L.B., Denoroy, L., Blessing, W.W., 1993. Loss of C1 and C3 epinephrine-synthesizing neurons in the medulla oblongata in Parkinson's disease. Ann. Neurol. 33, 357-367.

Goldstein, D.S., 2003. Dysautonomia in Parkinson's disease: neurocardiological abnormalities. Lancet Neurol. 2, 669-676.

Guyenet, P.G., 2006. The sympathetic control of blood pressure. Nat. Rev. Neurosci. 7, 335-346. ed.^eds., England.

Guyenet, P.G., Stornetta, R.L., Bochorishvili, G., Depuy, S.D., Burke, P.G., Abbott, S.B., 2013. C1 neurons: the body's EMTs. Am. J. Physiol. Regul. Integr. Comp. Physiol. 305, R187-R204.

Halpern, W., Mulvany, M.J., 1977. Tension responses to small length changes of vascular smooth muscle cells [proceedings]. J. Physiol. 265, 21p-23p.

Hassan, S.F., Zumut, S., Burke, P.G., McMullan, S., Cornish, J.L., Goodchild, A.K., 2015. Comparison of noradrenaline, dopamine and serotonin in mediating the tachycardic and thermogenic effects of methamphetamine in the ventral medial prefrontal cortex. Neuroscience 295, 209-220.

Huangfu, D.H., Koshiya, N., Guyenet, P.G., 1991. A5 noradrenergic unit activity and sympathetic nerve discharge in rats. Am. J. Physiol. 261, R393-R402.

Jeon, B.S., Jackson-Lewis, V., Burke, R.E., 1995. 6-Hydroxydopamine lesion of the rat substantia nigra: time course and morphology of cell death. Neurodegeneration 4, 131-137.

Kang, B.J., Chang, D.A., Mackay, D.D., West, G.H., Moreira, T.S., Takakura, A.C., Gwilt, J.M., Guyenet, P.G., Stornetta, R.L., 2007. Central nervous system distribution of the transcription factor Phox2b in the adult rat. J. Comp. Neurol. 503, 627-641.

Koshiya, N., Guyenet, P.G., 1994. A5 noradrenergic neurons and the carotid sympathetic chemoreflex. Am. J. Physiol. 267, R519-R526.

Kuo, Y.M., Li, Z., Jiao, Y., Gaborit, N., Pani, A.K., Orrison, B.M., Bruneau, B.G., Giasson, B.I., Smeyne, R.J., Gershon, M.D., Nussbaum, R.L., 2010. Extensive enteric nervous system abnormalities in mice transgenic for artificial chromosomes containing Parkinson disease-associated alpha-synuclein gene mutations precede central nervous system changes. Hum. Mol. Genet. 19, 1633-1650.

Loewy, A.D., McKellar, S., Saper, C.B., 1979. Direct projections from the A5 catecholamine cell group to the intermediolateral cell column. Brain Res. 174, 309-314.
Lu, S.F., Young, H.J., Lin, M.T., 1995. Nigrostriatal dopamine system mediates baroreflex sensitivity in rats. Neurosci. Lett. 190, 17-20.

McDowell, K., Chesselet, M.F., 2012. Animal models of the non-motor features of Parkinson's disease. Neurobiol. Dis. 46, 597-606.

Niewinski, P., Tubek, S., Banasiak, W., Paton, J.F., Ponikowski, P., 2014. Consequences of peripheral chemoreflex inhibition with low-dose dopamine in humans. J. Physiol. 592, 1295-1308.

Oliva, W.M., Granjeiro, E.M., Bongamba, L.G., Mendes, R.A., Machado, B.H., 2010. Dopamine microinjected into brainstem of awake rats affects baseline arterial pressure but not chemoreflex responses. Auton. Neurosci. 155, 73-81.

Paton, J.F., Li, Y.W., Schwaber, J.S., 2001. Response properties of baroreceptive NTS neurons. Ann. N. Y. Acad. Sci. 940, 157-168.

Pattyn, A., Morin, X., Cremer, H., Goridis, C., Brunet, J.F., 1997. Expression and interactions of the two closely related homeobox genes Phox2a and Phox $2 \mathrm{~b}$ during neurogenesis. Development 124, 4065-4075.

Pattyn, A., Morin, X., Cremer, H., Goridis, C., Brunet, J.F., 1999. The homeobox gene Phox $2 \mathrm{~b}$ is essential for the development of autonomic neural crest derivatives. Nature 399, 366-370.

Paxinos, G., Watson, C., 1998. The Rat Brain in Stereotaxic Coordinates, vol. 4. Academic Press, San Diego.

Robin, E.D., McCauley, R., 1992. Nitroprusside-related cyanide poisoning. Time (long past due) for urgent, effective interventions. Chest 102, 1842-1845.

Saper, C.B., Sorrentino, D.M., German, D.C., de Lacalle, S., 1991. Medullary catecholaminergic neurons in the normal human brain and in Parkinson's disease. Ann. Neurol. 29, 577-584.

Schreihofer, A.M., Guyenet, P.G., 1997. Identification of C1 presympathetic neurons in rat rostral ventrolateral medulla by juxtacellular labeling in vivo. J. Comp. Neurol. 387, 524-536.

Schreihofer, A.M., Guyenet, P.G., 2000. Sympathetic reflexes after depletion of bulbospinal catecholaminergic neurons with anti-DbetaH-saporin. Am. J. Physiol. Regul. Integr. Comp. Physiol. 279, R729-R742.

Stornetta, R.L., Moreira, T.S., Takakura, A.C., Kang, B.J., Chang, D.A., West, G.H. Brunet, J.F., Mulkey, D.K., Bayliss, D.A., Guyenet, P.G., 2006. Expression of Phox $2 \mathrm{~b}$ by brainstem neurons involved in chemosensory integration in the adult rat. J. Neurosci. 26, 10305-10314. ed.^eds., United States.

Takakura, A.C., Moreira, T.S., Colombari, E., West, G.H., Stornetta, R.L., Guyenet, P.G., 2006. Peripheral chemoreceptor inputs to retrotrapezoid nucleus (RTN) $\mathrm{CO}_{2}$ sensitive neurons in rats. J. Physiol. 572, 503-523. ed.^eds., England.

Takakura, A.C., Barna, B.F., Cruz, J.C., Colombari, E., Moreira, T.S., 2014. Phox2bexpressing retrotrapezoid neurons and the integration of central and peripheral chemosensory control of breathing in conscious rats. Exp. Physiol. 99, 571-585.

Takatsu, H., Nishida, H., Matsuo, H., Watanabe, S., Nagashima, K., Wada, H., Noda, T. Nishigaki, K., Fujiwara, H., 2000. Cardiac sympathetic denervation from the early stage of Parkinson's disease: clinical and experimental studies with radiolabeled MIBG. J. Nucl. Med. 41, 71-77.

Tipre, D.N., Goldstein, D.S., 2005. Cardiac and extracardiac sympathetic denervation in Parkinson's disease with orthostatic hypotension and in pure autonomic failure. J. Nucl. Med. 46, 1775-1781.

Truong, D.D., Bhidayasiri, R., Wolters, E., 2008. Management of non-motor symptoms in advanced Parkinson disease. J. Neurol. Sci. 266, 216-228.

Tuppy, M., Barna, B.F., Alves-Dos-Santos, L., Britto, L.R., Chiavegatto, S., Moreira, T.S. Takakura, A.C., 2015. Respiratory deficits in a rat model of Parkinson's disease. Neuroscience 297, 194-204.

Velseboer, D.C. de Haan, R.J., Wieling, W., Goldstein, D.S., de Bie, R.M., 2011. Prevalence of orthostatic hypotension in Parkinson's disease: a systematic review and meta-analysis. Parkinsonism Relat. Disord. 17, 724-729.

Weston, M., Wang, H., Stornetta, R.L., Sevigny, C.P., Guyenet, P.G., 2003. Fos expression by glutamatergic neurons of the solitary tract nucleus after phenylephrine-induced hypertension in rats. J. Comp. Neurol. 460, 525-541.

Wolters, E.C.h., 2009. Non-motor extranigral signs and symptoms in Parkinson's disease. Parkinsonism Relat. Disord. 15 (Suppl. 3), S6-S12. 